\title{
Relationship between Spot and Future Prices of Crude Oil: A Cointegration Analysis
}

\author{
M. C. Minimol \\ Rajagiri Centre for Business Studies, Rajagiri College of Social Sciences (Autonomous), Kochi, India \\ Email: minimol@rajagiri.edu
}

How to cite this paper: Minimol, M.C. (2018) Relationship between Spot and Future Prices of Crude Oil: A Cointegration Analysis. Theoretical Economics Letters, 8, 330-339.

https://doi.org/10.4236/tel.2018.83023

Received: December 12, 2017

Accepted: February 8, 2018

Published: February 11, 2018

Copyright (c) 2018 by author and Scientific Research Publishing Inc. This work is licensed under the Creative Commons Attribution International License (CC BY 4.0).

http://creativecommons.org/licenses/by/4.0/

\section{cc) (i) Open Access}

\begin{abstract}
The study was intended to reveal the relationship among the spot and future price of crude oil, which in turn will help in determining the prices of crude oil. While structuring a portfolio, high correlation among assets alone cannot be taken as a satisfactory measure for long run diversification paybacks. There is a crucial need to enhance the traditional risk-return modeling methodologies by giving due consideration to common long term trends among the asset prices. Considering this pressing need, the present paper attempts to explore the long run and short run relationship between spot and future prices of crude oil using time series data. To estimate the long and short run dynamics of crude oil prices, the present study applies the Johansen cointegration, and vector error correction modelling to time series analysis.
\end{abstract}

\section{Keywords}

Spot Price, Future Price, Crude Oil, Asset Prices, Cointegration, Vector Error Correction Model

\section{Introduction}

Asset allocation is perceived as one of the most significant and strategic decision to be taken by an investor or a fund manager. Asset allocation is about the proportion of investment in a class of asset in the portfolio. While deciding the portfolio, the fund manager has to decide on the types of asset to be included in the portfolio [1]. The portfolio theory suggests that an asset having low or negative correlation with other assets in the portfolio should be included in the portfolio to ensure optimum performance of the portfolio. Correlation being a short run relationship indicator; the key issue faced by an investor or fund manager is how to integrate the long term considerations in the asset selection process [2]. 
Traditional risk-return relationship models revealed that any long term trends in the data can be removed by differencing the series, but none of these traditional risk-return models include the decisions based on long term common trends in the price data [3]. To integrate this long run effect in portfolio creation, the present study adopted cointegration technique developed by Johansen [4] [5] [6] and Johansen and Juselius [7]. Correlation reflects co-movements that are expected to be in the short run and to have instabilities over time. So, correlation based portfolio strategies demand repeated revisions and adjustments to recuperate the portfolio performance. As against this, cointegration indicates long run relationship between asset prices that may occur even when correlation among the assets is very low or even static. The high correlation of returns need not necessarily indicate high cointegration in the prices. Thus, diversification decisions based on cointegration analysis may be more effective in the long term. Inclusion of assets that are not cointegrated would result in a more effective portfolio which does not require frequent revisions in the portfolio.

There is growing interest in finding out the relationship between the spot and future prices of oil and other commodities because of the long term implications resulting from commodity price movements. The commodity market for oil has experienced higher levels of volatility ever since the first oil crises reported in the 1970s. Last few years witnessed record oil prices and climate-change-related interest in biofuels, which in turn have resulted in search for explanations in this area. High commodity prices, whether or not related to oil prices, have obvious effects on purchasing power and economic growth [8] [9]. This study is an attempt to look at the behavior of spot and future prices of crude oil by using cointegration analysis.

The structure of this paper is as follows. Section 2 addresses the relevant literature and the objective of the study. Section 3 shows the model and empirical evidence drawn from the regression, cointegration tests, Granger causality tests and VECM estimations. Conclusions are provided in Section 4.

\section{Review of Literature}

A good number of empirical studies confirm the low correlation among commodity futures and other asset classes over certain periods of time [10] [11] [12] [13] [14]. Following the above studies, Ankrim \& Hensel [15], Lummer \& Laurence [16], and Satyanarayan \& Varangis [17] proved that commodity futures provide a good diversification to the portfolio of equity and bond. Anson [18] found out that commodity futures are valuable assets for risk-averse investor, but the amount of investment in commodity futures depends upon certain factors like utility functions, level of risk tolerance and portfolio composition. Simon [19] has modeled the conditional relationships between the Goldman Sachs Total Return Commodity Index and Sub-Indexes and the S\&P 500 index using the bivariate GARCH framework and the results indicate that while the diversification benefits of commodities have diminished over the sample period, the es- 
timated conditional correlations remain low enough for commodities to provide meaningful diversification benefits to equity investors.

Stelios \& Cees [20] investigates the linear and nonlinear causal linkages between daily spot and futures prices for maturities of one, two, three and four months of West Texas Intermediate (WTI) crude oil. The data cover two periods October 1991-October 1999 and November 1999-October 2007, with the latter being significantly more turbulent. Apart from the conventional linear Granger test they apply a new nonparametric test for nonlinear causality by Diks and Panchenko after controlling for cointegration. In addition to the traditional pairwise analysis, they test for causality while correcting for the effects of the other variables. To check if any of the observed causality is strictly nonlinear in nature, they also examine the nonlinear causal relationships of VECM filtered residuals. Finally, they investigate the hypothesis of nonlinear non-causality after controlling for conditional heteroskedasticity in the data using a GARCH-BEKK model. Whilst the linear causal relationships disappear after VECM cointegration filtering, nonlinear causal linkages in some cases persist even after GARCH filtering in both periods. This indicates that spot and futures returns may exhibit asymmetric GARCH effects and/or statistically significant higher order conditional moments. Moreover, the results imply that if nonlinear effects are accounted for, neither market leads or lags the other consistently, videlicet the pattern of leads and lags changes over time.

Maslyuk \& Smyth [21] examined whether crude oil spot and futures prices of the same and different grades are cointegrated using a residual-based cointegration test that allows for one structural break in the cointegrating vector and high-frequency data. They choose the US WTI and the UK Brent as the representative crudes for this analysis since these two crudes have well-established spot and futures markets. We find that spot and future prices of the same grade as well as spot and futures prices of different grades are cointegrated. They investigated the potential causes of structural change as revealed by the cointegration test in terms of events that have impacted on world oil markets as well as discuss the implications of the results for hedge managers, investors and regulators.

Huang, Yang \& Hwang [22] segments daily data from January of 1986 to April of 2007 into three periods based on certain important events. Both periods I and II indicate that the spot prices in general are higher than futures prices as was well-known in the literature. Only period-III displays a reverse phenomenon: futures prices, in general, exceed spot prices. When the absolute value of a basis (futures-spot) is greater than the threshold value in the arbitrage area (regime 1 and 3), at least one of the error correction coefficients, representing adjustment towards equilibrium, is statistically significant. That is, there exists a tendency in the oil market in which prices move toward equilibrium. Wang \& Wu [23] found out that crude oil spot and futures prices are cointegrated only when the price differentials are larger than the threshold value. They use a multi-frequency analy- 
sis based on low-pass filtering with different cut-off frequencies. The main findings indicate that the relationships between spot and futures prices are different between in the short-term and in the long-term. In the short-term, futures price plays the major role in the formation of long-run equilibrium (error correction mechanism). In the long-term, both spot and futures prices contribute to the dynamics of long-run equilibrium.

Ghaith and Awad [24], investigated the possible long-term relationship between the prices of crude oil and food commodities represented by maize, wheat, sorghum, soybean, barley, linseed oil, soybean oil, and palm oil. Time series econometric techniques (Unit root tests, Co-integration, and Granger causality) were applied. The study utilized monthly data over the period of 1980 to 2009 . The results of this study reveal that there is a strong evidence of long-term relationship between crude oil and the food commodities prices. A traditional Granger Causality is used to check whether causality exists between two product prices. The outcome suggests that there is unidirectional causality between the prices crude oil and some of the food commodities under examination.

\section{The Model and Empirical Evidence}

The study attempts to provide evidences on the extent to which the spot and future price of crude oil move together, so that the investor is able to take better investment decisions. The study is conducted, by giving due consideration to the perspective of an investor while analyzing the relationship between spot and future prices. Modern portfolio theory suggests that the relevant information matrix for such an investor includes the expected asset returns, the variability of these returns, as well as cross-asset correlations. Additionally, leads or lags in the time series make correlations almost useless. For example, if the data is lagged by one or two days some of the daily time series, the effect on the correlation between the series will be significant, the correlation might even turn from positive to negative. On the other side, the effect on the common long term relationship between the series will be minimal. Cointegration allows for short term divergence between two different time series, meaning that in a day to day basis, the series does not necessarily have to go up or down at the same time, one might go up while the other goes down, thus there is no need for the two series to move in daily synchrony at all. In the long run, however the two price series cannot wander off in opposite directions for very long without coming back to their long term equilibrium. The distinction between stationary and non-stationary time series is extremely important because stationarity is a precondition to make statistical inferences. If the mean or variance of time series change with time, then it is impossible to generalize results from regressions made for a specific period of time into a different period of time. So, it is necessary to identify whether the time series is stationary or not before making any statistical inference. If one performs regression analysis on time series where the dependent, independent, or both variables have a unit root process, then the results will have no economic signi- 
ficance, in particular, the estimates will be biased and the results of hypothesis tests will be invalid. This is the problem of spurious regression which was first reported back in 1926 by Yule. In order to confirm stationarity of the series, Augmented Dickey Fuller test was conducted. To analyze long-term cointegration, the study made use of the daily closing prices for both spot and future. The study was based on the methods of Johansen's cointegration analysis. The idea for the analysis is that if two series each follow upward trend, then, in general, they will diverge in the long run. The data analysis comprises of four parts: 1) testing for a unit root; 2) testing for the number of cointegrating vectors in the systems of asset prices, provided the null hypothesis of a unit root for every series is not rejected; 3 ) testing the vector autoregression between the assets; and 4) testing the causality effect among the two assets.

\section{Unit Root Test}

To test for a unit root in each series, the researcher employed the Augmented Dickey-Fuller (ADF) [25] Test. The tests are conducted with and without a deterministic trend $(t)$. The general form of ADF test is estimated by the following regression

$$
\Delta Y_{t}=\alpha_{0}+Z_{t}+\alpha_{1} Y_{t-1}+\sum \alpha_{t} \Delta Y_{t-1}+\varepsilon_{t}
$$

where $\alpha_{0}$ is constant, $t$ is a deterministic trend, and enough lagged differences ( $p$ ) are included to ensure that the error term becomes white noise. If the autoregressive representation of $Y_{t}$ contains a unit root, the t-ratio for $\alpha_{1}$ should be consistent with the hypothesis, $\alpha_{1}=0$. The results of unit root test are presented in Table 1.

Reading from Table 1 above and applying the decision rule, we can conclude that both the variables are stationary at first order of integration. Hence, the time series of these variables are deemed fit to be used for estimating regression model at the order of integration for which they are stationary.

\section{Johansen Cointegration Test}

To investigate the existence of a long-term relationship between spot and future prices of crude oil, cointegration analysis was performed. If the spot and future prices are cointegrated with one another, then this will provide statistical evidence for the existence of a long-run relationship. Though, a set of economic series are not stationary, there may exist some linear combination of the variable

Table 1. Results of unit root test.

\begin{tabular}{ccccc}
\hline \multirow{2}{*}{ S/N } & Variables & \multicolumn{2}{c}{ ADF Fisher Chi-square } & \multirow{2}{*}{ Order of Integration } \\
\cline { 3 - 3 } & & Critical Values & Probability Values & \\
\hline 1 & Crude Oil Spot & -4.6448 & & $\mathrm{I}(1)$ \\
2 & Crude Oil Spot & -5.1771 & $\mathrm{I}(1)$ \\
\hline
\end{tabular}

Sources: Unit Root Test, Eviews 8. 
which exhibit a dynamic equilibrium in the long run [26]. The study employed the maximum-likelihood test procedure established by Johansen and Juselius [7]. Specifically, if $Y_{t}$ is a vector of $n$ stochastic variables, then there exists a p-lag vector auto regression with Gaussian errors of the following form:

$$
\Delta Y_{t}=k+\gamma_{1} \Delta Y_{t-1}+\cdots+\gamma_{\rho-1} \Delta Y_{t-\rho+1}+\Pi Y_{t-1}+z_{t}
$$

where $\gamma_{1}, \cdots, \gamma_{p-1}$ and $\Pi$ are coefficient matrices, $z_{t}$ is a vector of white noise process and $\mathrm{k}$ contains all deterministic elements.

The focal point of conducting Johansen's cointegration tests is to determine the rank $(r)$ of matrix $\gamma_{k}$. In the present application, there are three possible outcomes. First, it can be of full rank, $(r=n)$, which would imply that the variables are stationary processes, which would contradict the earlier finding of nonstationarity. Second, the rank of $k$ can be zero $(r=0)$, indicating that there is no long-run relationship among the variables. In instances when $\gamma_{k}$ is of either full rank or zero rank, it will be appropriate to estimate the model in either levels or first differences, respectively.

Finally, in the intermediate case when there are at most $r$ cointegrating vectors $0 \leq r \leq n$ (i.e., reduced rank), it suggests that there are $(n-r)$ common stochastic trends. The number of lags used in the vector Error Correction model is chosen based on the evidence provided by Akaike's Information Criterion. The cointegration procedure yields two likelihood ratio test statistics, referred to as the maximum eigenvalue ( $\lambda$-max) test and the trace test, which will help in determining which of the possibilities is supported by the data. Unrestricted Cointegration Trace statistic and Max-Eigen statistic are established to determine whether cointegration exists. The results are given in Table 2 and Table 3.

Johansen Cointegration results can be studied either on the basis of Trace value or Max Eigen value. From the above table, trace value indicates that there is no cointegration at level as p-value of 0.0000 is less than 0.05 and critical value (15.49471) is less than the trace statistic (63.22908), therefore the study fails to accept the null hypothesis that there is no cointegration equation among the variables. On the similar lines, Max-eigen value also indicates existence of cointegration by rejecting the null hypothesis that there is zero cointegration equations among the variables, with p-value 0.0000 less than 0.05 and critical value (14.36460) is less than the max eigen statistics (38.18780). Therefore, both the tests indicate that there exists cointegration among spot and future prices of crude oil.

\section{VECM and Granger Causality}

If the variables are found to be cointegrated in long run, then the next step is to employ vector error correction model followed by the granger causality. The vector error correction (VECM) is commonly used for forecasting systems of interrelated time series and for analyzing the dynamic impact of random disturbances on the system of variables. The optimum lag length is identified using Akaike Information Criteria (AIC). The VECM approach sidesteps the need for structural 
Table 2. Unrestricted cointegration rank test (trace).

\begin{tabular}{cccc}
\hline Hypothesized No. of CE $(\mathrm{s})$ & Trace Statistic & 0.05 Critical Value & Probability Value \\
\hline None & 63.22908 & 15.49471 & 0.0000 \\
At most 1 & 24.45403 & 9.841466 & 0.0000 \\
At most 2 & 14.2237 & 7.75366 & 0.0000 \\
At most 3 & 8.2251 & 4.81889 & 0.0000 \\
At most 4 & 2.91598 & 3.85613 & 0.0033 \\
At most 5 & 0.032623 & 2.79707 & 0.0566 \\
\hline
\end{tabular}

Source: Johansen Cointegration Test, Eviews 8.

Table 3. Unrestricted cointegration rank test (maximum eigenvalue).

\begin{tabular}{cccc}
\hline Hypothesized No. of CE(s) & Max-Eigen Statistic & 0.05 Critical Value & Probability Value \\
\hline None & 38.18780 & 14.36261 & 0.0000 \\
At most 1 & 24.18396 & 3.23142 & 0.0000 \\
At most 2 & 13.99862 & 2.07757 & 0.0000 \\
At most 3 & 11.30912 & 1.87687 & 0.0000 \\
At most 4 & 9.58975 & 1.58434 & 0.0273 \\
At most 5 & 0.00109 & 1.13162 & 0.1236 \\
\hline
\end{tabular}

Source: Johansen Cointegration Test, Eviews 8.

modelling by treating every endogenous variable in the system as a function of the lagged values of all of the endogenous variables in the system.

Consider two time-series variables, $y t$ and $x t$. Generalizing the discussion about dynamic relationships to these two interrelated variables yields a system

$$
\begin{aligned}
& y t=\beta 10+\beta 11 y t^{-1}+\beta 12 x t^{-1}+v t^{y} \\
& x t=\beta 20+\beta 21 y t^{-1}+\beta 22 x t^{-1}+v t^{x} .
\end{aligned}
$$

The equations describe a system in which each variable is a function of its own lag, and the lag of the other variable in the system. The results VECM are shown in Table 4.

No coefficient in the table has probability value of 0.05 or less, this implies there is no short-run relationship among the variables used in the model.

\section{Regression Model}

The results of regression model estimated shows that there exist a positive relationship between the spot price and future price of crude oil. Future price of crude oil would be 11.89638 when the spot price of crude oil is assumed to be zero. When spot price increases by 1 percent, Future price of crude oil increases approximately by 88 percent. The model shows that the explanatory variable captured in the model explained 97 percent of the variations as $\mathrm{R}^{2}$ is 0.9715 . The result of OLS regression model is presented below (Table 5):

$$
\text { CRUDE_FUTURE }=\beta_{0}+\beta_{1} \text { CRUDE_SPOT }+\mu_{i t}
$$


Table 4. Vector error correction model.

\begin{tabular}{ccc}
\hline Error Correction & D(CRUDE_SPOT) & D(CRUDE_FUTURE) \\
\hline CointEq1 & -0.736710 & -0.670553 \\
& $(0.30153)$ & $(0.33631)$ \\
D(CRUDE_SPOT $(-1))$ & {$[-2.44321]$} & {$[-1.99385]$} \\
& 0.341176 & 0.271840 \\
D(CRUDE_SPOT $(-2))$ & $(0.52064)$ & $(0.58068)$ \\
& {$[0.65531]$} & {$[0.46814]$} \\
D(CRUDE_FUTURE $(-1))$ & 0.825303 & 1.134791 \\
& $(0.51736)$ & $(0.57703)$ \\
& {$[1.59522]$} & {$[1.96661]$} \\
D(CRUDE_FUTURE $(-2))$ & -0.138169 & -0.115614 \\
& $(0.46906)$ & $(0.52316)$ \\
& {$[-0.29457]$} & {$[-0.22099]$} \\
& -0.804160 & -1.113752 \\
& $(0.46236)$ & $(0.51569)$ \\
& {$[-1.73924]$} & {$[-2.15973]$} \\
\hline
\end{tabular}

Sources: Vector Error Correction Model, E Views 8.

Table 5. OLS for spot and future prices of crude oil.

Dependent Variable: FUTURE_PRICE

\begin{tabular}{ccccc}
\hline Method: Least Squares & & & \\
\hline Variable & Coefficient & Std. Error & t-Statistic & Prob. \\
\hline C & 11.89638 & 1.783911 & 6.668704 & 0.0000 \\
SPOT_PRICE & 0.879634 & 0.019619 & 44.83672 & 0.0000 \\
R-squared & 0.971488 & Mean dependent var & 91.27033 \\
Adjusted R-squared & 0.971005 & S.D. dependent var & 10.09249 \\
S.E. of regression & 1.718537 & Akaike info criterion & 3.953061 \\
Sum squared resid & 174.2487 & Schwarz criterion & 4.022270 \\
Log likelihood & -118.5684 & Hannan-Quinn criter. & 3.980184 \\
F-statistic & 2010.332 & Durbin-Watson stat & 0.504490 \\
Prob(F-statistic) & 0.000000 & & \\
\hline
\end{tabular}

Sources: Regression Analysis, E Views 8.

$$
\text { CRUDE_FUTURE }=11.89638+0.879634 \mathrm{CRUDE} \_\mathrm{SPOT}+\mu_{i t} .
$$

The regression coefficient is statistically significant, therefore, it can be concluded that spot price causes future price of crude oil in long run. These results reconfirm the results of cointegration analysis. 


\section{Conclusion}

The study examined both the short run and long run relationship between spot and future prices of crude oil, so that crude oil futures could be considered as a diversification tool for investors to earn an extra return by using the data across 2009-2014. The analysis shows that there is a strong correlation among the two variables and the two variables are also found to be cointegrated, resulting in evidences for long term relation between the two variables meaning that the two series share a common stochastic move. If a passive investor includes crude oil futures to the traditional crude oil spot, he/she would be able to earn high return in lieu of low risk. The present study supports the diversifying properties of commodity futures. Future research can be conducted in other commodities, so that the results can be more generalized.

\section{References}

[1] Bansal, Y., Kumar, S. and Verma, P. (2014) Cointegration and Causality between Equity and Commodity Futures: Implications for Portfolio Diversification. Global Journal of Management and Business Research, 14, 35-44.

[2] Kasa, K. (1992) Common Stochastic Trends in International Stock Markets. Journal of Monetary Economics, 29, 95-124. https://doi.org/10.1016/0304-3932(92)90025-W

[3] Alexander, C. (1999) Optimal Hedging Using Cointegration. Philosophical Transactions of the Royal Society, 357, 2039-2058. https://doi.org/10.1098/rsta.1999.0416

[4] Johansen, S. (1988) Statistical Analysis of Cointegrating Vectors. Journal of Economic Dynamics and Control, 12, 231-254. https://doi.org/10.1016/0165-1889(88)90041-3

[5] Johansen, S. (1991) Estimation and Hypothesis Testing of Cointegrating Vectors in Gaussian Vector Autoregression Models. Econometrica, 59, 1551-1580. https://doi.org/10.2307/2938278

[6] Johansen, S. (1992) Determination of Cointegration Rank in the Presence of a Linear Trend. Oxford Bulletin of Economics and Statistics, 54, 383-397. https://doi.org/10.1111/j.1468-0084.1992.tb00008.x

[7] Johansen, S. and Juselius, K. (1990) Maximum Likelihood Estimation and Inference on Cointegration with Applications to the Demand for Money. Oxford Bulletin of Economics and Statistics, 52, 169-210. https://doi.org/10.1111/j.1468-0084.1990.mp52002003.x

[8] Chaudhuri, K. (2001) Long-Run Prices of Primary Commodities and Oil Prices. Applied Economics, 33, 531-538. https://doi.org/10.1080/00036840122106

[9] Zhang, Z., Lohr, L., Escalante, C. and Wetzstein, M. (2010) Food Versus Fuel: What Do Prices Tell Us? Energy Policy, 38, 445-451.

[10] Bodie, Z. and Rosansky, V. (1980) Risk and Returns in Commodity Futures. Financial Analysts Journal, 36, 27-39. https://doi.org/10.2469/faj.v36.n3.27

[11] Erb, C. and Harvey, C.R. (2005) The Tactical and Strategic Value of Commodity Futures. NBER Working Paper 11222.

[12] Gorton, G. and Rouwenhorst, K. (2006) Facts and Fantasies about Commodity Futures. Financial Analysts Journal, 62, 47-68. https://doi.org/10.2469/faj.v62.n2.4083 
[13] Buyuksahin, B., Michael, S.H. and Michel, A.R. (2010) Commodities and Equities: Ever a Market of One? Journal of Alternative Investments, 12, 75-95.

[14] Chong, J. and Joelle, M. (2010) Conditional Return Correlations between Commodity Futures and Traditional Assets. Journal of Alternative Investments, 12, 61-75.

[15] Ankrim, E.M. and Hensel, C.R. (1993) Commodities in Asset Allocation: A Real Asset Alternative to Real Estate? Financial Analysts Journal, 49, 20-29.

[16] Lummer, S.L. and Laurence, B.S. (1993) GSCI Collateralized Futures: A Hedging and Diversification Tool for Institutional Investors. Journal of Investing, 2, 75-82. https://doi.org/10.3905/joi.2.2.75

[17] Satyanarayan, S. and Panos, V. (1996) Diversification Benefits of Commodity Assets in Global Portfolios. Journal of Investing, 5, 69-78. https://doi.org/10.3905/joi.5.1.69

[18] Anson, M. (1999) Maximizing Utility with Commodity Futures Diversification. Journal of Portfolio Management, 25, 86-94. https://doi.org/10.3905/jpm.1999.319753

[19] Simon, D.P. (2013) A Conditional Assessment of the Relationships between Commodity and Equity Indexes. The Journal of Alternative Investments, 16, 30-51. https://doi.org/10.3905/jai.2013.16.2.030

[20] Bekiros, S.D. and Diks, C.G.H. (2008) The Relationship between Crude Oil Spot and Future Prices: Cointegration, Linerar and Nonlinear Causality. Energy Economics, 30, 2673-2685. https://doi.org/10.1016/j.eneco.2008.03.006

[21] Maslyuk, S. and Smyth, R. (2009) Cointegration between Oil Spot and Future Prices of the Same and Different Grades in the Presence of Structural Change. Energy Policy, 37, 1687-1693. https://doi.org/10.1016/j.enpol.2009.01.013

[22] Huang, B.N., Yang, C.W. and Hwang, M.J. (2009) The Dynamics of a Nonlinear Relationship between Crude Oil Spot and Futures Prices: A Multivariate Threshold Regression Approach. Energy Economics, 31, 91-98. https://doi.org/10.1016/j.eneco.2008.08.002

[23] Wang, Y. and Wu, C. (2013) Are Crude Oil Spot and Futures Prices Cointegrated? Not Always! Economic Modelling, 33, 641-650. https://doi.org/10.1016/j.econmod.2013.05.013

[24] Ghaith, Z. and Award, I.M. (2011) Examining the Long Term Relationship between Crude Oil and Food Commodity Prices: Cointegration and Causality. International Journal of Economics and Management Sciences, 1, 62-72.

[25] Dickey, D.A. and Fuller, W.A. (1981) Likelihood Ratio Statistics for Autoregressive Time Series with a Unit Root. Econometrica, 49, 1057-1072. https://doi.org/10.2307/1912517

[26] Engle, R.F. and Granger C.W.J. (1987) Cointegration and Error Correction: Representation, Estimation and Testing. Econometrica, 55, 251-276. https://doi.org/10.2307/1913236 